\title{
Central Trial Communication Material
}

National Cancer Institute

\section{Source}

National Cancer Institute. Central Trial Communication Material. NCI Thesaurus. Code

C115596.

A collection of central trial-related communication agreements, significant discussions, or relevant information. 